\title{
Stress distribution in the knee joint in relation to tibiofemoral angle using the finite element method
}

\author{
Robert Karpiński ${ }^{1, *}$, Łukasz Jaworski ${ }^{2}$, Józef Jonak ${ }^{1}$, and Przemysław Krakowski ${ }^{3}$ \\ ${ }^{1}$ Lublin University of Technology, Faculty of Mechanical Engineering, Department of Machine Design and Mechatronics, \\ Nadbystrzycka 36, 20-618, Lublin, Poland \\ ${ }^{2}$ Independent researcher, Lublin, Poland \\ ${ }^{3}$ Orthopaedic Department, Łęczna Hospital, Krasnystawska 52, 21-010 Łęczna, Poland
}

\begin{abstract}
The article presents the results of a preliminary study on the structural analysis of the knee joint, considering changes in the mechanical properties of the articular cartilage of the joint. Studies have been made due to the need to determine the tension distribution occurring in the cartilage of the human knee. This distribution could be the starting point for designing custom made human knee prosthesis. Basic anatomy, biomechanical analysis of the knee joint and articular cartilage was introduced. Based on a series of computed tomography $[\mathrm{CT}]$ scans, the 3D model of human knee joint was reverse-engineered, processed and exported to $\mathrm{CAD}$ software. The static mechanical analysis of the knee joint model was conducted using the finite element method [FEM], in three different values of tibiofemoral angle and with varying mechanical properties of the cartilage tissue. Main conclusions of the study are: the capability to absorb loads by articular cartilage of the knee joint is preliminary determined as decreasing with increasing degenerations of the cartilage and with age of a patient. Without further information on changes of cartilage's mechanical parameters in time it is hard to determine the nature of relation between mentioned capability and these parameters.
\end{abstract}

\section{Introduction}

Osteoarthritis is one of the most common diseases diagnosed by general practitioners and orthopaedic surgeons [1]. It is a complex process, in which degeneration of articular cartilage, subchondral bone and synovium can be observed. Alterations in these tissues lead to joint disfunctions [2,3]. Main symptoms of osteoarthritis include pain, stiffness of affected joint, which impair daily activities. Conditions such as obesity, joint overload, smoking, trauma or hormonal dysregulation have impact on onset of arthritic changes $[4,5]$. Obesity increases loads which have to be transmitted through lower extremity joints. Knee joint, which is the biggest joint in the human body is highly susceptible to osteoarthritic changes due to its location, function and mechanical properties. Therefore, research society is looking for possible ways to delay or even stop osteoarthritic changes. For this purpose, a throughout recognition of each factor influencing gait and knee mechanics is crucial. In vivo testing of mechanical properties of human joints rise controversies in an ethical manner. Therefore, progress in the development of numerical methods used in medicine makes it possible to collect necessary data without the need of in vivo human joint testing [6-10].

\section{Anatomy and biomechanics of knee joint}

Knee joint is the biggest joint in the human body and one of the most susceptible to injuries and degenerative changes. Due to its localisation between femur and tibia it plays a vital role in everyday activities such as walking, kneeling or rising from a seated position. Knee joint is a modified hinge joint, which articular surfaces are created by lateral and medial femoral and tibial condyles and articular surface of patella. As in every joint, the articular surfaces are covered with articular cartilage. Articular cartilage is an avascular and aneural, connective tissue which enables smooth and painless joint movement. Knee can be divided into two coworking joints namely: tibiofemoral and patellofemoral joints. Patella which is the largest sesamoid bone, has a concave articular surface, and slides along a femoral sulcus of the distal femur. Patella is dynamically and statically stabilised by its lateral and medial retinaculum and quadriceps muscle and its attachments. The tibiofemoral joint which is created by articulating condyles of femur and tibia can be classified as a modified hinge joint, in which additional movement such as sliding occurs [11]. Medial femoral condyle and a corresponding tibial surface is longer than in the lateral compartment. Moreover, the medial tibial articular

*Corresponding author: r.karpinski@pollub.pl 
surface is concave in contrast to convex lateral tibial plateau. This bony anatomy is responsible for a screwhome mechanism of the knee, which locks the knee in full extension [12]. Stability of the knee joint is achieved by cooperation of static and dynamic stabilisers such as ligaments and muscles. There is disagreement among orthopaedic society about the number, location or structure of knee ligaments with new concepts being developed $[13,14]$ and old verified. It is widely accepted that the knee joint is one of the most complex joints of the human body. Therefore, a proper analysis of the function and relations between anatomical structures during movement is essential for better understanding of the knee kinematics. The most crucial part of every synovial joint is articular cartilage, which due to its unique properties enables smooth and painless motion. However, chondrocytes which are main cellular component of hyaline cartilage are subjected to heavy loads during gait in a cyclic manner. The articular cartilage has very limited capacity for regeneration [15]. Chondrocytes constitute only $1 \%$ to $5 \%$ of cartilage volume $[15,16]$.

As mentioned above, articular cartilage has a unique architecture. It is composed of 4 layers which differ significantly in particular components concentration and distribution, as seen in fig. 1. The superficial layer occupies $10-20 \%$ of the cartilage thickness. Collagen fibres in this layer are organised parallel to the articular surface in contrast to deeper layers. Superficial zone has lower proteoglycan concentration when compared to the deeper regions of cartilage [17]. The zone has also higher concentration of chondrocytes, which are flat and parallel to the surface. The internal organisation of the superficial layer is prepared for highest deformation ratio and therefore is most resilient to shear forces. Moreover, the superficial layer has the greatest water concentration reaching $74 \%$ [18]. The transitional zone of the cartilage, which constitutes $40-60 \%$ of the cartilage thickness, distribution of cells and molecules is less organised and the collagen fibres are thicker than in superficial zone [19]. Chondrocytes in this zone are more metabolically active, synthesise greater amounts of proteoglycans. The deep layer of the cartilage has the greatest proteoglycans concentration and constitutes around $30 \%$ of cartilage thickness. It is the layer which deals with compressive loads. Chondrocytes of this layer and collagen fibres lay perpendicular to the articular surface and to the calcified chondral layer which attaches articular cartilage to the subchondral bone. The concentration of the proteoglycans and collagen fibres is strongly correlated with mechanical properties of the human articular cartilage [20]. In order to provide adequate number of necessary molecules constant remodelling of the cartilage takes place.

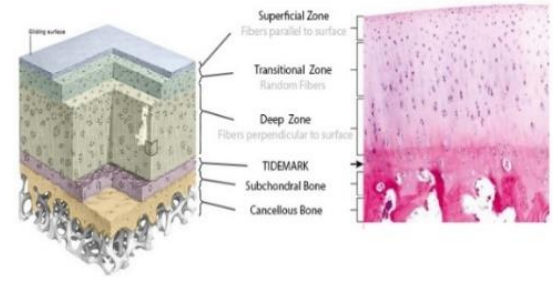

Fig. 1. Cartilage layers [11].
The unique architecture of cartilage has an effect on its mechanical properties. As a whole tissue, cartilage is highly anisotropic. The elastic modulus of articular cartilage ranges from 0,3 up to $1,5 \mathrm{MPa}[21,22]$. Nevertheless, peak values of stress up to $18 \mathrm{MPa}$ can be measured in joints under dynamic loading [23]. The cartilage is capable of withstanding such loads due to its low permeability. Water connected with the proteoglycans and stored inside the cartilage matrix in healthy cartilage cannot be pressed out of the tissue. Therefore, the dynamic stiffness of cartilage can be much higher than intrinsic modulus of the tissue [24]. In the knee joint tibial and femoral cartilage move against each other. In this complex movement femoral articular surface contacts, compresses and slides over the tibial articular surface. As a result of applying load, articular cartilage deforms. During everyday activities such as knee bending or running cartilage can compress up to $6 \%$ of its thickness [25, 26]. However, values of tissue deformation can increase significantly when cartilage is tested in vitro. In vitro studies show that deformation of $44 \%$ is achievable in intact healthy articular cartilage in static loading [27]. Moreover, its mechanical properties depend on the depth of the cartilage. Changes in mechanical properties are caused by differences in architecture and composition of cartilage zones. The compressive modulus changes throughout the depth of cartilage. It rises from superficial to the deep zone. In bovine articular cartilage the increase of 27 times was measured [28]. The tensile modulus of articular cartilage on the contrary is higher in the superficial zone reaching $10 \mathrm{MPa}$ than in middle zone $5,4 \mathrm{MPa}$, which is caused by better organisation of collagen network in superficial zone [29]. Articular cartilage not only is resilient to different kinds of loads, which are to be transmitted by it, but also has very low friction [30], which is attributed to lubrication by synovial fluid.

As mentioned above, articular cartilage is crucial for transmitting loads during everyday activities. For vast majority the forces which are transmitted through the knee reach around oscillate between $220 \%$ - $350 \%$ of body weight [31]. However, during work or recreational sports, knee joint is subjected to great loads exceeding 7 times body weight during kneeling [32]. Moreover, incorrect squatting technique can rise peek loads over 30\% [33]. The link between high loads transmitted by the knee and osteoarthritis is well known [34]. However, the exact mechanism of osteoarthritic progression is not established, while many possible causes are taken under consideration [34]. While osteoarthritis being one of the most debilitating disease in older population [35], it is advisable to seek new screening methods, which might facilitate early diagnose. Vibroacoustic testing seems to be a good, non-invasive modality [36], however correlation between modelled and examined knee joints must establish its utility in the process of diagnosis.

\section{Methodology of the study}

Based on a series of computed tomography scans, which were imported in DICOM file format to Materialise MIMICS software, it was possible to calculate a 3D geometry of a tibia and a femur bone. As a result of an 
insufficient quality of received scans, the preliminary models were not suited for further analyses, hence a necessity of a further processing, which was conducted in Materialise 3-matic software, directly connected to MIMICS, and providing control over the parameters of a 3D model. Processed models were then ready to import in STEP file format to Dassault Systemes Solidworks CAD software. Here 3D files were merged into an assembly comprising of partial tibia and partial femur bone with a simplified model of a cartilage between mentioned structures [37-39].

Obtained models were then subjected to preliminary analyses using finite element method in Solidworks Simulation module.

\subsection{FEA method}

Finite Element Analysis (FEA) is one of methods of conducting simulations for solving engineering. Its main operating principle is based on a division of analysed model into finite amount of simpler parts, leading to a creation of a discrete model. In the course of an analysis other physical quantities influencing the model, such as loads, restraints are being digitised as well. After the discretisation process the calculation begins, during which individual elements are being united as a whole using equilibrium conditions and displacement compatibilities, which results in an acquisition of algebraic, simultaneous equations being a mathematical description of analysed problem. Afterwards, these equations are solved using values of equilibrium conditions, and their outcome used to compute sought quantities, i.e. tensions and stress distribution or deformation of a body [41-44].

\subsection{Boundary conditions}

In order to achieve credible results, materials were assigned to each element. Two cases were considered the healthy cartilage of an adult, 40 to 59 years old person, and the degenerated, ossified cartilage with properties similar to the cone tissue. Properties of materials are presented in Table 1. To achieve the best coherence with anatomical structure, the model was then constrained on the upper surface of the femur bone; then connecting pairs between bones and cartilage were established.

Table 1. Properties of materials [5].

\begin{tabular}{|c|c|c|c|c|}
\hline Material & Element & $\begin{array}{c}\text { Young } \\
\text { modulus } \\
{[\mathrm{MPa}]}\end{array}$ & $\begin{array}{c}\text { Poisson's } \\
\text { ratio [-] }\end{array}$ & $\begin{array}{c}\text { Density } \\
{[\mathrm{kg} / \mathrm{m} 3]}\end{array}$ \\
\hline $\begin{array}{c}\text { Bone } \\
\text { tissue }\end{array}$ & $\begin{array}{c}\text { Femur, } \\
\text { tibia }\end{array}$ & 17600 & 0,3 & 1020 \\
\hline $\begin{array}{c}\text { Cartilage } \\
\text { age 40-59 }\end{array}$ & Cartilage & 123 & 0,35 & 500 \\
\hline
\end{tabular}

The force acting on the system was applied on the bottom surface of the tibia and was equal to $820 \mathrm{~N}$ and was induced in three following positions of the patient's joint: $0^{\circ}, 45^{\circ}$ flexion and $-5^{\circ}$ hyperextension. Given the complexity of introduced models, it was crucial to generate a sufficient mesh grid. The complete mesh grid contained 32150 nodes and 21137 elements, with element size equal 5,63 $\pm 0,28 \mathrm{~mm}$. The model before an analysis can be seen in Fig. 2.

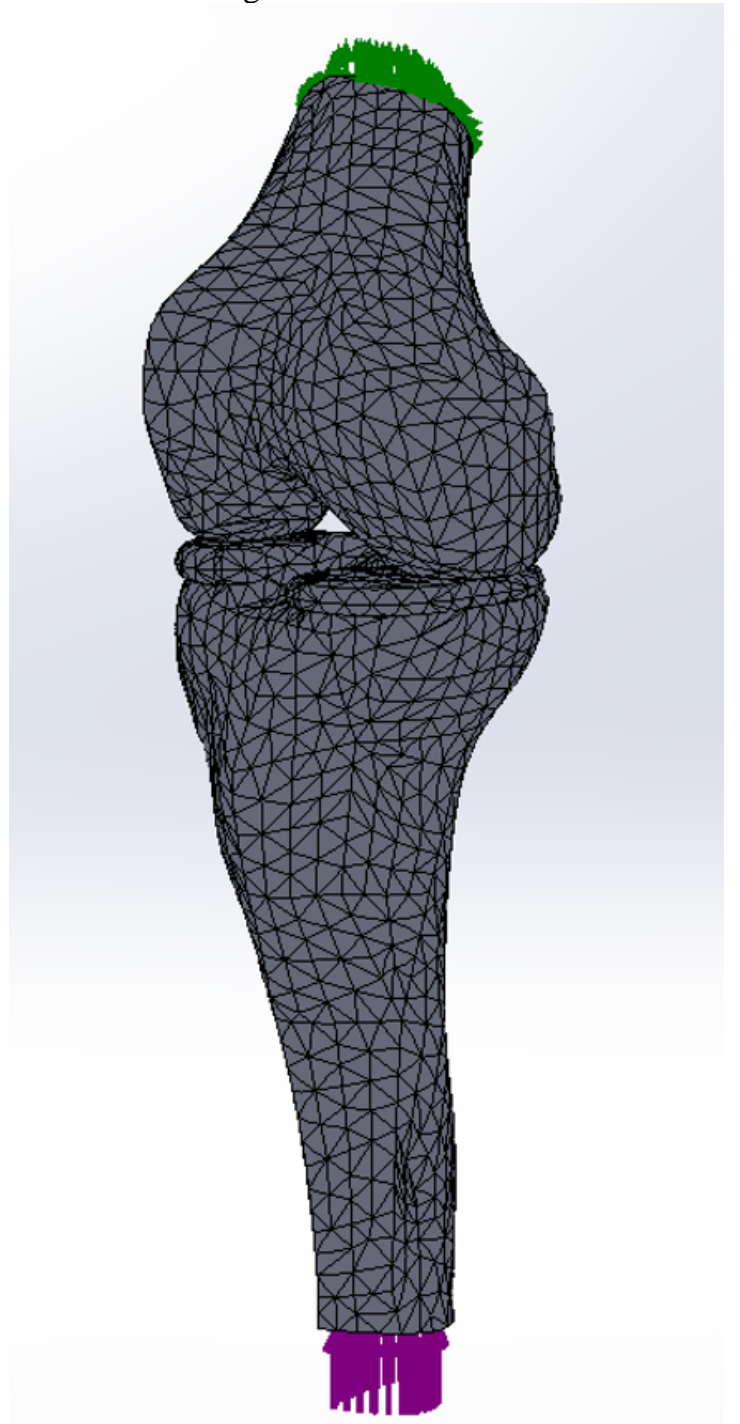

Fig. 2. The constrained model with applied forces.

\subsection{Results}

In assessing results of conducted analyses, maps of stress distribution and maximum values of induced stresses in cartilage were taken under consideration.

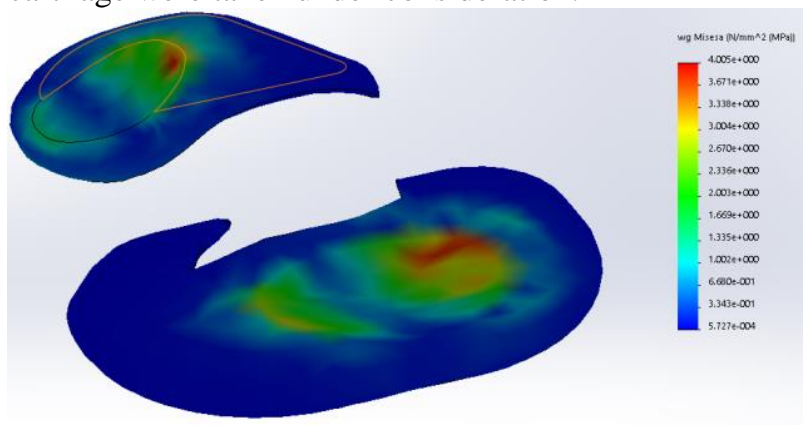

Fig. 3. Stress distribution on upper surface of healthy cartilage for $0^{\circ}$ position. 


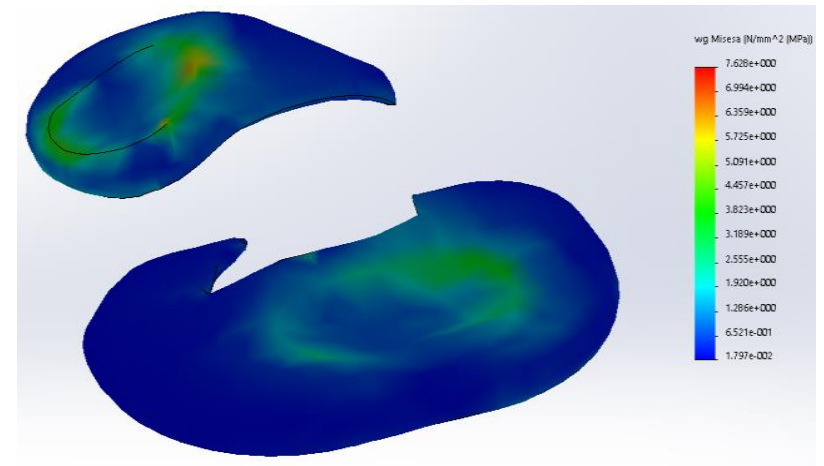

Fig. 4. Stress distribution on upper surface of degenerated cartilage for $0^{\circ}$ position

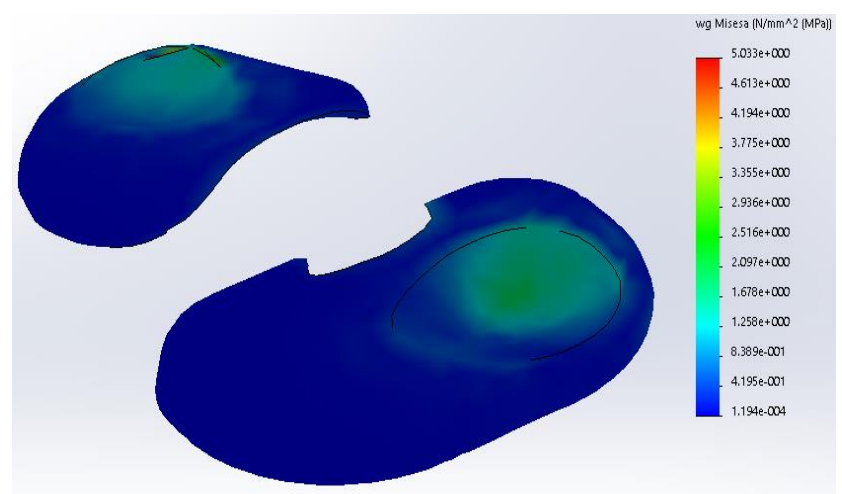

Fig. 5. Stress distribution on upper surface of healthy cartilage for $45^{\circ}$ flexion .

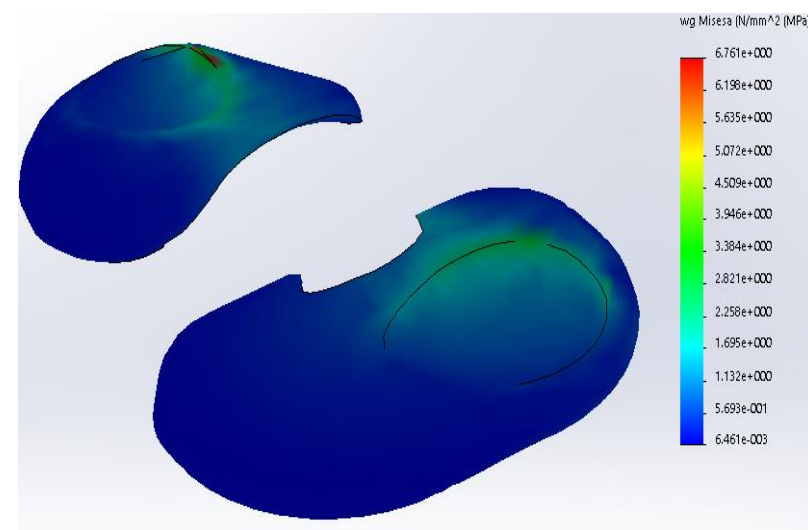

Fig. 6. Stress distribution on upper surface of degenerated cartilage for $45^{\circ}$ flexion.

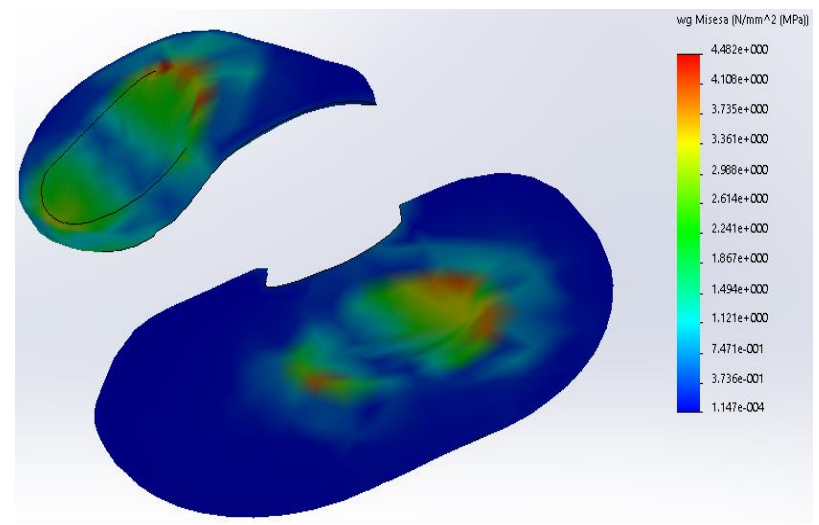

Fig. 7. Stress distribution on upper surface of healthy cartilage for $-5^{\circ}$ hyperextension .

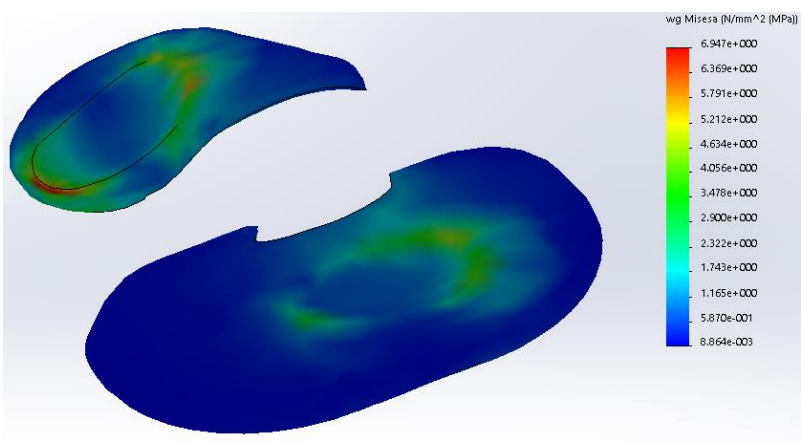

Fig. 8. Stress distribution on upper surface of degenerated cartilage for $-5^{\circ}$ hyperextension.

Table 2. Maximum values of stress for conducted analyses $[\mathrm{MPa}]$.

\begin{tabular}{|c|c|c|}
\hline Position & $\begin{array}{c}\text { Healthy } \\
\text { cartilage }\end{array}$ & $\begin{array}{c}\text { Degenerated } \\
\text { cartilage }\end{array}$ \\
\hline $0^{\circ}$ & 4,005 & 7,628 \\
\hline $45^{\circ}$ & 5,033 & 6,761 \\
\hline$-5^{\circ}$ & 4,482 & 6,947 \\
\hline
\end{tabular}

As it can be seen in Fig. 3 - 8, mechanical properties of the cartilage have an impact on stress distribution - in healthy cartilage loads are distributed on larger part of a connecting surface, while in case of degenerated cartilage loads tend to accumulate near edges of the connecting surface. A change in mechanical properties leads to increase in stress values in cartilage, which is especially seen in standing position $\left(0^{\circ}\right)$, where the difference between mentioned values is almost twofold. In both flexion and hyperextension, the difference is not as significant, yet it is still visible.

\section{Conclusion}

Performed analyses shows that the ability to absorb loads by articular cartilage seems to decrease as a result of degeneration of tissue and ageing of the patient. Differences were the biggest in the standing position. This may explain why extension is the first movement to be lost during arthritic process. The way of presenting the results proposed in the work provides additional information about the mechanics of the knee joint. It can be used as an additional diagnostic tool to help assess the condition of the cartilage. Implementation of virtual models of damaged or affected skeletal elements, and subsequent numerical analyses is very important at the stage of surgical planning while selecting the necessary equipment and allows for a more accurate description of the case when communicating with the patient, which may be particularly useful in contact with older patients, suffering from limited mobility.

In order to determine the exact relationships describing the dependence of changes in mechanical parameters between the articular cartilage absorption capacity, it is necessary to perform a wider, multi-aspect studies including both mechanics as well as physiological changes taking place in the tissue structure. A more suitable and advanced approach would be to implement a hyperelastic material model in finite elements analysis in order to simulate the cartilaginous tissue more accurately. 
Another way would be to consider a bone, especially around an articular surface, as a sort of composite material consisting different types of bone structures, which could lead to more exact transfer of forces between elements in a joint.

\section{References}

1. T. Neogi, Osteoarthritis and Cartilage. 21, 11451153 (2013)

2. S. Glyn-Jones, A. Palmer, R. Agricola, A. Price, T. Vincent, H. Weinans, A. Carr, Lancet. 386, 376-87 (2015)

3. M. Conconi, E. Halilaj, V. Parenti Castelli, J. Crisco, Journal of Biomechanics. 47, 3787-93 (2014)

4. V. Silverwood, M. Blagojevic-Bucknall, C. Jinks, J. L. Jordan, J. Protheroe, K. P. Jordan, Osteoarthritis and Cartilage. 23, 507-515 (2015)

5. R. Karpiński, Ł. Jaworski, J. Zubrzycki, Advances in Science and Technology Research Journal. 10, 240-246 (2016)

6. J. Zubrzycki, R. Karpinski, L. Jaworski, A. M. Ausiyevich, N. Smidova, Science \& Technique. 17, 165-172 (2018)

7. P. Gargiulo, T. Pétursson, B. Magnússon, P. Bifulco, M. Cesarelli, G. M. Izzo, G. Magnúsdóttir, G. Halldórsson, G. K. Ludvigsdóttir, J. Tribel, H. Jónsson, Artificial Organs. 37, 567-573 (2013)

8. P. Krukow, M. Harciarek, J. MorylowskaTopolska, H. Karakuła-Juchnowicz, K. Jonak, Cognitive Neuropsychiatry. 22, 391-406 (2017)

9. P. Gargiulo, Í. Árnadóttir, M. Gíslason, K. Edmunds, I. Ólafsson, Journal of Healthcare Engineering. 2017, 1-8 (2017)

10. P. Krukow, K. Jonak, H. Karakuła-Juchnowicz, A. Podkowiński, K. Jonak, M. Borys, M. Harciarek, Psychiatry Research: Neuroimaging. 275, 28-35 (2018)

11. J. Goodfellow, J. O'Connor, J Bone Joint Surg Br. 60-B, 358-369 (1978)

12. H. Y. Kim, K. J. Kim, D. S. Yang, S. W. Jeung, H. G. Choi, W. S. Choy, Clinics in Orthopedic Surgery. 7, 303 (2015)

13. R. Śmigielski, U. Zdanowicz, M. Drwięga, B. Ciszek, A. Williams, The Bone \& Joint Journal. 98B, 1020-1026 (2016)

14. M. I. Kennedy, S. Claes, F. A. F. Fuso, B. T. Williams, M. T. Goldsmith, T. L. Turnbull, C. A. Wijdicks, R. F. LaPrade, The American Journal of Sports Medicine. 43, 1606-1615 (2015)

15. E. Hunziker, T. Quinn, H. Hauselmann, Osteoarthritis and Cartilage. 10, 564-572 (2002)

16. M. B. Goldring, Best Practice \& Research Clinical Rheumatology. 20, 1003-1025 (2006)

17. J. Malda, K. E. M. Benders, T. J. Klein, J. C. de Grauw, M. J. L. Kik, D. W. Hutmacher, D. B. F.
Saris, P. R. van Weeren, W. J. A. Dhert, Osteoarthritis and Cartilage. 20, 1147-1151 (2012)

18. M. Venn, A. Maroudas, Annals of the Rheumatic Diseases. 36, 121-129 (1977)

19. J. M. Clark, Journal of Orthopaedic Research. 9, 246-257 (1991)

20. S. Knecht, B. Vanwanseele, E. Stüssi, Clinical Biomechanics. 21, 999-1012 (2006)

21. J. P. Arokoski, M. M. Hyttinen, H. J. Helminen, J. S. Jurvelin, J. Biomed. Mater. Res. 48, 99-107 (1999)

22. V. C. Mow, M. H. Holmes, W. Michael Lai, Journal of Biomechanics. 17, 377-394 (1984)

23. W. A. Hodge, R. S. Fijan, K. L. Carlson, R. G. Burgess, W. H. Harris, R. W. Mann, Proc. Natl. Acad. Sci. U.S.A. 83, 2879-2883 (1986)

24. J. S. Jurvelin, M. D. Buschmann, E. B. Hunziker, $J$ Biomech. 30, 235-241 (1997)

25. U. G. Kersting, J. J. Stubendorff, M. C. Schmidt, G.-P. Brüggemann, Osteoarthritis and Cartilage. 13, 925-934 (2005)

26. F. Eckstein, M. Hudelmaier, R. Putz, Journal of Anatomy. 208, 491-512 (2006)

27. C. Herberhold, S. Faber, T. Stammberger, M. Steinlechner, R. Putz, K. H. Englmeier, M. Reiser, F. Eckstein, J Biomech. 32, 1287-1295 (1999)

28. R. M. Schinagl, D. Gurskis, A. C. Chen, R. L. Sah, Journal of Orthopaedic Research. 15, 499-506 (1997)

29. S. Akizuki, V. C. Mow, F. Müller, J. C. Pita, D. S. Howell, D. H. Manicourt, Journal of Orthopaedic Research. 4, 379-392 (1986)

30. A. Unsworth, D. Dowson, V. Wright, Journal of Lubrication Technology. 97, 369 (1975)

31. I. Kutzner, B. Heinlein, F. Graichen, A. Bender, A. Rohlmann, A. Halder, A. Beier, G. Bergmann, Journal of Biomechanics. 43, 2164-2173 (2010)

32. N. J. Dahlkvist, P. Mayo, B. B. Seedhom, Eng Med. 11, 69-76 (1982)

33. S. M. Smith, R. A. Cockburn, A. Hemmerich, R. M. Li, U. P. Wyss, Gait \& Posture. 27, 376-386 (2008)

34. L. M. Tennant, H. C. Chong, S. M. Acker, Ergonomics. 61, 839-852 (2018)

35. M. Cross, E. Smith, D. Hoy, S. Nolte, I. Ackerman, M. Fransen, L. Bridgett, S. Williams, F. Guillemin, C. L. Hill, L. L. Laslett, G. Jones, F. Cicuttini, R. Osborne, T. Vos, et al., Annals of the Rheumatic Diseases. 73, 1323-1330 (2014)

36. D. Bączkowicz, E. Majorczyk, $P M \& R$. 8, 1065 1071 (2016)

37. K. Torres, G. Staśkiewicz, M. Śnieżyński, A. Drop, R. Maciejewski, Folia Morphologica. 70, 1-4 (2011)

38. P. Potamianos, A. A. Amis, A. J. Forester, M. McGurk, M. Bircher, Proceedings of the Institution 
of Mechanical Engineers, Part H: Journal of Engineering in Medicine. 212, 383-393 (1998)

39. M. Frame, J. S. Huntley, The Scientific World Journal. 2012, 1-7 (2012)

40. R. Karpiński, Ł. Jaworski, J. Zubrzycki, ITM Web Conf. 15, 07015 (2017)

41. K. Falkowicz, ITM Web of Conferences. 15, 07013 (2017)
42. R. Karpiński, Ł. Jaworski, M. Szala, M. Mańko, ITM Web Conf. 15, 07006 (2017)

43. K. Falkowicz, Archives of Civil Engineering. 63, 161-172 (2017)

44. P. Rozylo, H. Debski, P. Wysmulski, K. Falkowicz, Compos Struct. 204, 207-216 (2018) 